Ductile-Brittle Transition Temperature Testing of Tungsten Using the Three-Point Bend Test

\author{
David H. Lassila \\ Frank Magness \\ Dennis Freeman
}

March 5, 1991

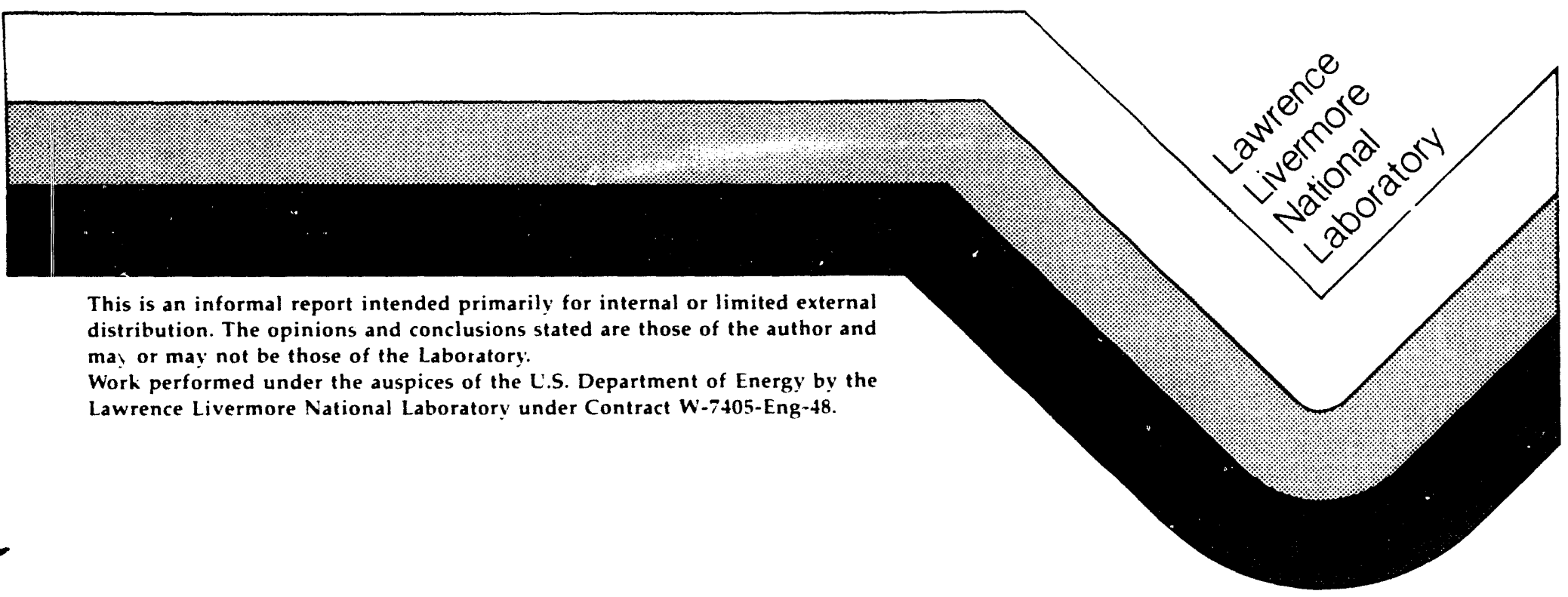




\section{DISCLAIMER}

This document was prepared as an acccount of work sponsored by an agency of the United States Government. Neither the United States Government nor the University of California nor any of their employees, makes any warranty. express or implied, or assumes any legal liability or responsibility for the accuracy, completeness, or usefulness of any information, apparatus, product, or process disclosed, or represents that its use would not infringe privately own rights. Reference herein to any specific commercial products, process, or service by trade name, trademark, manufacturer, or otherwise, does not necessarily constitute or imply its endorsement, recommendation, or favoring by the United States Government or the University of California. The views and opinions of authors expressed herein do not necessarily state or reflect those of the United States Government or the University of California, and shall not be used for advertising or product endorsement purposes.

This report has been reproduced directly from the best available copy.

Available to DOE and DOE contractors from the Office of Scientific and Technical Information P.O. Box 62, Oak Ridge, TN 37831

Prices available from (615) 576-8401, FTS 626-8401

Available to the public from the National Technical Information Service

U.S. Department of Commerce 5285 Port Royal Rd.,

Springfield, VA 22161 


\title{
Ductile-Brittle Transition Temperature Testing of Tungsten \\ Using the Three-Point Bend Test
}

David H. Lassila

UCRL-ID--108258

Frank Magness

DE92 000099

Dennis Freeman

Engineering Sciences Division

LLNL

March 5, 1991

\begin{abstract}
Three-point bend tests were performed to determine the Ductile-Brittle Transition Temperatures (DBTTs) of forged and chemical vapor deposition (CVD) tungsten. Testing was performed under quasi-static conditions at temperatures between $23^{\circ} \mathrm{C}$ and $450^{\circ} \mathrm{C}$ using a forced-air environmental chamber. Load-displacement data from the three-point bend tests indicated that the constitutive behavior of the materials tested varied considerably. Finite element modeling of the three-point bend test was performed to investigate plastic strains induced in the samples during testing as a function of constitutive behavior. The modeling assumed plane stress conditions in the sample and simple bi-linear elastic-plastic constitutive behavior of the test material. The strains induced in the samples were found to be functions of both the yield stress and work hardening behavior of the materials. The use of the three-point bend test to determine DBTT, and the DBTTs reported for the test materials, are discussed relative to the modeling results. It is concluded that the three-point bend test has some utility in the determination of DBTTs if some caution is used in the selection of test parameters and fixture geometries. However, the three-point bend test does not provide a complete picture of the nature of the ductilebrittle transition.
\end{abstract}

* Work performed under the auspices of the U. S. Department of Energy by the Lawrence Livermore National Laboratory under contract No. W-7405-ENG-48. 


\section{INTRODUCTION}

The ductile-brittle transition behavior of BCC refractory metals such as tungsten is a well established phenomenon (1). The transition from ductile to brittle fracture behavior occurs over a range of temperature, typically about $100 \mathrm{C}$, however in many studies a single ductile-brittle transition temperature (DBTT) is reported. Below the DBTT the fracture behavior is brittle and little or no macroscopic plastic deformation occurs prior to fracture. Above the DBTT a large amount of tensile plastic deformation can proceed prior to failure which is initiated by necking of the material.

Several test techniques have been used to determine the DBTT, for example, tensile testing (2), fracture mechanics type testing such as Charpy impact testing (3), and bend testing of bar samples (4). Of these test techniques, the three-point bend test is the most inexpensive and simplest to perform. Also, this test can be successfully performed on relatively small geometries, which in some cases can be a necessity if the test material is of small dimensions. The disadvantages associated with the three-point bend test are, however, numerous. The test data has been shown to be sensitive to surface finish of the test sample (5) and the strains induced in the test sample are a function of the sample and test fixture geometries. Also, as will be shown in this paper through computer modeling of the threepoint bend test, the maximum stresses and strains in the sample are sensitive to the constitutive behavior of the test material. These features of the test technique can lead to difficulties in interpreting the test data and defining DBTTS.

In this work, we examine the utility of the three-point bend test applied for the determination of DBTTs of five tungsten materials. First, the three-point bend test is described and fracture and load-displacement data is presented. Results of computer modeling of the three-point bend test, as performed in this work, are then presented. The computer modeling results and the test data are then discussed and a strain based criterion for the DBTT using the three-point bend test data is defined.

\section{EXPERIMENTAL}

Three-point bend tests were performed on a total of five different tungsten samples, three of which were warm-forged powder metallurgy products and two of which were chemical vapor deposited materials. The microstructure, fracture surface morphologies and fracture 
surface impurity segregation analyses of these materials have been previously reported (6). The three-point bend test fixture used in this work had $12.7 \mathrm{~mm}$ diameter loading points. The distance between the outer loading points was $32 \mathrm{~mm}$. Test samples $2.54 \mathrm{~mm}$ thick and $7.62 \mathrm{~mm}$ wide and of sufficient length to accommodate the test fixture were used. The surfaces of the test samples were ground to an 8-rms surface finish and the edges of the samples were broken with a finishing stone.

Testing was performed in a forced-air heater unit at temperatures up to $450^{\circ} \mathrm{C}$. All sample and test fixture contact surfaces were lubricated with boron nitride powder prior to testing. The relative displacement rate of the test fixture loading points was $4.3 \times 10^{-2} \mathrm{~cm} / \mathrm{sec}$. and the maximum relative displacement was $6.35 \mathrm{~mm}$. Based on the results of finite element modeling of the three-point bend tests, which will be discussed subsequently, the strain rate of the outer fiber of the test sample was approximately $10^{-3} \mathrm{~s}^{-1}$.

The axial load as a function of the fixture displacement was recorded for all of the tests. The load-displacement curves for the tests performed on material WF-1 at various temperatures are given in Figure 1 and indicate elastic-plastic response of the test material at test temperatures greater than $50^{\circ} \mathrm{C}$. The following expression was derived using simple elastic beam theory and can be used to estimate the yield stress (SY) of a material from the load-displacement curves;

$$
\sigma=\frac{3}{2} \frac{P L}{w t^{2}}
$$

where $t$ and $w$ are the thickness and width of the test sample respectively, $L$ is the outer span of the loading fixture, and $\mathrm{P}$ is the load at which yielding occurs. The yield strengths of the test materials based on this analysis are given in Table 1. As expected, for a given material the yield stresses typically decreased with increase in test temperature.

The maximum displacements from the three-point bend tests are plotted against test temperature in Figure 2. In other work reported in the literature, displacement vs. temperature plots (or bend-angle vs. temperature plots) are used to estimate DBTTs. In this work a strain based criterion for the DBTT was used. Strains produced in the samples during testing were estimated by finite element modeling of the bend test which is discussed in the next section. 


\section{COMPUTER MODELING}

A simple kinematic mechanics analysis can be used to derive the maximum value of strain $\varepsilon_{m}$ in a beam which is bent around a cylinder. This maximum strain is a function of the thickness of the beam and the diameter of the cylinder and is,

$$
\varepsilon_{m}=\frac{t}{D+t}
$$

where $t$ is the thickness of the sample and $D$ is the diameter of the cylinder. Using the appropriate values for $t$ and $D$ the maximum strain is calculated to be $5.66 \%$. This analysis assumes that the neutral axis of bending is located in the mid-plane of the sample and does not change position. It is also assumed that the sample conforms to the cylindrical geometry of the center loading fixture, hereafter referred to as the loading cylinder.

To provide a more complete analysis of strains and stresses, a two dimensional finite element code, NIKE2D(7), was used to model the three-point bend test. NIKE2D is an implicit code well suited for analyzing system or material response to large, quasi-static deflections. In the computer model a plane-stress condition in the thickness-width plane of the sample was assumed. The mesh is shown in Figure 3 relative to a global cartesian coordinate system and the results of the analyses are reported relative to this system. The material model used in the calculations for the test material was bi-linear (elastic-plastic) with a Young's modulus of $393 \mathrm{GPa}$. A simple elastic model was used for the cylindrical rods which support and deflect the sample in these tests. NIKE2D allows the introduction of slidelines between parts in contact. For this analysis, individual slidelines were defined between each of the rods and the tungsten sample. A coefficient of friction equal to 0.06 (11) was used to simulate a lubricated interface between the test sample and the loading fixtures.

Displacement boundary conditions are imposed on the center rod, moving it $0.76 \mathrm{~cm}$ in a series of 100 discrete increments. Plot states were recorded at every other increment and stored in binary plot files which were then read by a post-processor (ORION) (12).

To assess the validity of the the plane stress assumption, the changes in width of a WF-2 test sample was compared with the computer model result ( $x$ displacements). As shown in 
Figure 4, the computer model prediction matched the actual lateral displacements of the test sample, indicating that the plane stress assumption was valid for this particular modeling.

Stress-strain behavior was determined for material WF- 2 by compression testing at strain rates of $10^{-3} \mathrm{~s}^{-1}$ and $3000 \mathrm{~s}^{-1}$ at room temperature and is shown in Figure $5(8)$. The computer model was first run with material behavior which approximated the slow strain rate constitutive behavior of material WF-2. The largest value of tensile strain $\left(\varepsilon_{m}\right)$ predicted for sample WF-2, which occurs as expected at the two surface elements at the center of the sample, is plotted as a function of displacement of the loading fixture and is shown as curve "a" in Figure 6. This plot indicates that $\varepsilon_{\mathrm{m}}$ in the sample reaches a maximum value of $5.8 \%$ at a test fixture displacement of $4.7 \mathrm{~mm}$. This result is in good agreement with the value predicted by Equation 2 . The $\varepsilon_{\mathrm{m}} \mathrm{vs}$. displacement plot for constitutive behavior that reflects that of the WF-1 material at a strain rate of $3000 \mathrm{~s}^{-1}$ is shown as curve "b" in Figure 6 . In this case $\varepsilon_{\mathrm{m}}$ reaches a maximum value of $8.5 \%$ at a displacement of $5.08 \mathrm{~mm}$. This much larger value of $\varepsilon_{\mathrm{m}}$ is the result of the development of a plastic hinge in the sample which results in the sample pulling away from the center support, as shown in Figure 7-b. The plastic hinge effect is a result of the lack of work hardening in the material at high strain rates which stems in part from the temperature sensitivity of the material's flow stress and the adiabatic condition at high strain rates.

To further investigate the effects of constitutive behavior on $\varepsilon_{\mathrm{m}}$ in the three-point bend sample, the effects of changes in work hardening, while holding the yield stress constant at $690 \mathrm{MPa}$ were determined and are shown in Figure 8-a. In the accompaning Figure 8-b, the maximum tensile stress $\left(\sigma_{m}\right)$ as a function of displacement is shown. $\sigma_{m}$ occurs in the same element and direction as $\varepsilon_{\mathrm{m}}$. The effects on $\varepsilon_{\mathrm{m}}$ and $\sigma_{\mathrm{m}}$ due to changing the work hardening, while holding yield strength constant at $100 \mathrm{MPa}$, are shown in Figures 9-a and 9-b respectively. Curves " $f$ " and " $g$ " reach high values of strain because the sample develops a plastic hinge and is not conforming to the loading cylinder.

The data presented in Figures 6,8 and 9 shows that the constitutive behavior of the test material can have a significant effect on $\varepsilon_{m}$ and $\sigma_{m}$ in the test sample. Also the maximum values of $\varepsilon_{\mathrm{m}}$ and $\sigma_{\mathrm{m}}$ can occur at different displacements of the test fixture. However, if the sample is taken through sufficient displacement and if the sample conforms to the loading cylinder, a relatively uniform value of $\varepsilon_{m}$ in a sample can be achieved. This value of $\varepsilon_{m}$ in the case of the different constitutive behaviors studied in this work will vary about $\pm 10 \%$ from the value given by Equation 2 . 
By taking into account the yield strengths of the tungsten materials (determined from the bend tests) and from the typical work hardening behavior of tungsten, it is expected that the maximum value of $\varepsilon_{\mathrm{m}}$ in any of the test samples which were bent through a displacement of $6.35 \mathrm{~mm}$ would be between $5.0 \%$ and $5.8 \%$. Based on this, the DBTT in this work is defined as the three-point bend test temperature at which a sample undergoes a minimum of $5.0 \%$ strain without failure. The DBTTs of the test materials are reported in Table 2.

\section{DISCUSSION}

The transition from brittle to ductile behavior when tungsten is deformed in tension occurs over a range of temperatures. The spread of temperatures over which the ductile-brittle transition occurs has been reported to be about $100^{\circ} \mathrm{C}$ for annealed tungsten (9). In other work upper and lower DBTTs are reported, the upper temperature referring to the test temperature at which no increase in ductility is observed, and the lower temperature referring to the temperature below which no decrease in ductility is observed (10). The DBTT criterion selected in this work corresponds to some temperature between fully brittle and fully ductile behavior. However, vrithout additional test data such as that provided by tensile testing, it is difficult to determine what increase in temperature over the reported DBTT, if any, would be required to realize fully ductile behavior in a given material.

The maximum value of tensile stress which occurs during the three-point bend test may play an important roll in the fracture of the test sample and consequently the DBTT determination for two reasons: 1) The brittle fracture mode is highly dependent on the maximum applied tensile stress and 2) the maximum tensile stress in the three-point bend test is dependent on the constitutive behavior of the test material. For example, the two CVD tungsten materials, CVD-C and CVD-L were found to have yield strengths of 632 $\mathrm{MPa}$ and $1206 \mathrm{MPa}$ at a test temperature of $400^{\circ} \mathrm{C}$. If we assume that the work hardening behavior of these materials is similar, the flow stress at any given strain (or displacement of the test fixture) of the CVD-L material would be considerably higher than that of the CVD$\mathrm{C}$ material, as shown in Figure 9b. The displacement vs. temperature curve of the CVD-L material, shown in Figure 2, lies below that of the CVD-C suggesting that the CVD-L material is more brittle than the CVD-C and also has a $\mathrm{r}$ igher DBTT than the CVD-C. However this interpretation is suspect because the stress acting to fracture the CVD-L material at a given strain or displacement will always be higher than that of the CVD-C 
material. If a stress based criterion were employed (i.e. replacing the displacement axis with a stress axis), the CVD-L material may lie well above that of the CVD-C material and the opposite conclusion regarding the relative ductility of these materials could be drawn.

\section{CONCLUSIONS}

The three-point bend test can be used to induce a predetermined amount of tensile strain in a material. The maximum value of $\varepsilon_{\mathrm{m}}$ can be estimated using Equation 1 and is believed to be within approximately $\pm 10 \%$ of the actual value for the bend tests reported in this work. Equation 1 is only valid if the sample conforms to the loading cylinder and the displacement of the three-point bend fixture is sufficient to induce the maximum value of $\varepsilon_{m}$. Low values of work hardening in a material, such as that which is typical of BCC materials under adiabatic/high-strain-rate deformation conditions, may result in values of $\varepsilon_{m}$ which are much greater than that predicted by Equation 1.

Clearly, the three-point bend test provides an incomplete picture of the transition from ductile to brittle fracture behavior and only a rough estimate of the DBTT. In this work a strain based criterion was employed to estimate a single value for the DETT using the threepoint bend test data. Additional testing, such as tensile or fracture mechanics testing, would be required to determine the temperature at which fully ductile fracture behavior is realized. 


\section{ACKNOWLEDGEMENTS}

This work was supported by DARPA Joint Armor-Antiarmor Program.

\section{REFERENCES}

1. For example see; "Refractory Metals and Alloys II", M. Semchyshen and I. Perlmutter eds., The Metallurgical Society/AIME, Interscience Publishers, New York, 1962.

2. P. L. Raffo, J. Less-Common Metals, 17, (1969), p 133.

3. Tran-Huu-Loi et al., J. Mat. Sci., 20, (1985), p 199.

4. K. Farrell, A. C. Schaffhauser and J. L. Stiegler, J. Less-Common Metals, 13, (1967), p 141.

5. J. R. Stephens, Rev. Deformation Behavior Materials, 1, (1974), p 31.

6. D. H. Lassila and A. Connor, UCRL-JC-106552, 1991.

7. J. O. Hallquist, LLNL, UCID-19677, Rev.1, (1986).

8. D. H. Lassila and M. LeBlanc, document in progress, Lawrence Livermore National Laboratory, Livermore, CA 1991.

9. J. H. Bechtold and P. G. Shewmon, Trans. Am. Soc. Metals, 46, (1954), p 397.

10. L. S. Kosachev et al., Phys. Metals Volume 6, 2, (1985), p 264.

11. Handbook of tables for applied Engineering Science, Second Edition, pp 610-612.

12. J. O. Hallquist and J. L Levatin, LLNL, UCID-19310, Rev. 2, (1985). 
Table 1

\begin{tabular}{|c|c|c|c|c|c|c|}
\hline & $\overline{M A X}$ & YIELD & YIELD & MAX. & TEST & \\
\hline SPECIMEN ID. & LOAD & LOAD & STRENGTH & DISP. & TEMP. & \\
\hline & (Nt) & (Nt) & $(\mathrm{MPa})$ & $(\mathrm{mm})$ & (degrees C) & \\
\hline \multirow[t]{4}{*}{ WF-1 } & 53.82 & - & - & 1.33 & 23 & broke \\
\hline & 52.49 & 46.71 & 1508.20 & 2.77 & 100 & broke \\
\hline & 50.26 & 47.51 & 1534.06 & 6.70 & 150 & bent \\
\hline & 39.14 & 36.48 & 1177.84 & 3.80 & 200 & bent \\
\hline & & & & & & \\
\hline \multirow[t]{7}{*}{ WF-2 } & 53.65 & - & - & 1.10 & 23 & broke \\
\hline & 64.99 & 59.61 & 1924.76 & 1.80 & 50 & broke \\
\hline & 62.81 & - & - & 1.43 & 50 & broke \\
\hline & 58.89 & 53.38 & 1723.66 & 2.46 & 100 & broke \\
\hline & 64.45 & 61.47 & 1985.08 & 2.20 & 100 & broke \\
\hline & 58.36 & 56.09 & 1811.28 & 5.82 & 150 & bent \\
\hline & 49.11 & 41.81 & 1350.20 & 6.05 & 200 & bent \\
\hline \multirow[t]{5}{*}{ WF-3 } & 43.59 & - & - & .87 & 23 & broke \\
\hline & 46.26 & - & - & 1.07 & 100 & broke \\
\hline & 50.26 & 43.59 & 1407.66 & 1.82 & 150 & broke \\
\hline & 53.02 & 40.92 & 1321.47 & 6.28 & 200 & bent \\
\hline & 39.81 & 33.81 & 1091.65 & 6.30 & 250 & bent \\
\hline \multirow{9}{*}{ CVD-C } & & & & & & \\
\hline & 24.91 & - & - & .55 & 23 & broke \\
\hline & 30.25 & - & - & .77 & 100 & broke \\
\hline & 29.80 & 27.58 & 890.56 & 1.46 & 200 & broke \\
\hline & 32.03 & 30.25 & 976.74 & 1.74 & 250 & broke \\
\hline & 25.80 & 17.79 & 574.55 & 2.25 & 300 & broke \\
\hline & 25.09 & 18.24 & 588.92 & 6.12 & 350 & bent \\
\hline & 28.20 & 19.57 & 632.01 & 6.35 & 400 & bent \\
\hline & & & & & & \\
\hline \multirow[t]{7}{*}{ CVD-L } & 33.36 & - & - & .73 & 23 & broke \\
\hline & 34.56 & - & $\overline{-}$ & .73 & 100 & broke \\
\hline & 43.15 & - & - & 1.35 & 200 & broke \\
\hline & 39.23 & 36.48 & 1177.84 & 2.84 & 300 & broke \\
\hline & 42.93 & 37.81 & 1220.93 & 4.13 & 350 & broke \\
\hline & 45.02 & 37.37 & 1206.56 & 5.83 & 400 & broke \\
\hline & 41.37 & 36.92 & 1192.20 & 5.30 & 450 & broke \\
\hline
\end{tabular}

Table 2

\begin{tabular}{c|c} 
Material & DBTT $\left({ }^{\circ} \mathrm{C}\right)$ \\
\hline WF-1 & 150 \\
WF-2 & 150 \\
WF-3 & 200 \\
CVD-C & 350 \\
CVD-L & $>450$
\end{tabular}




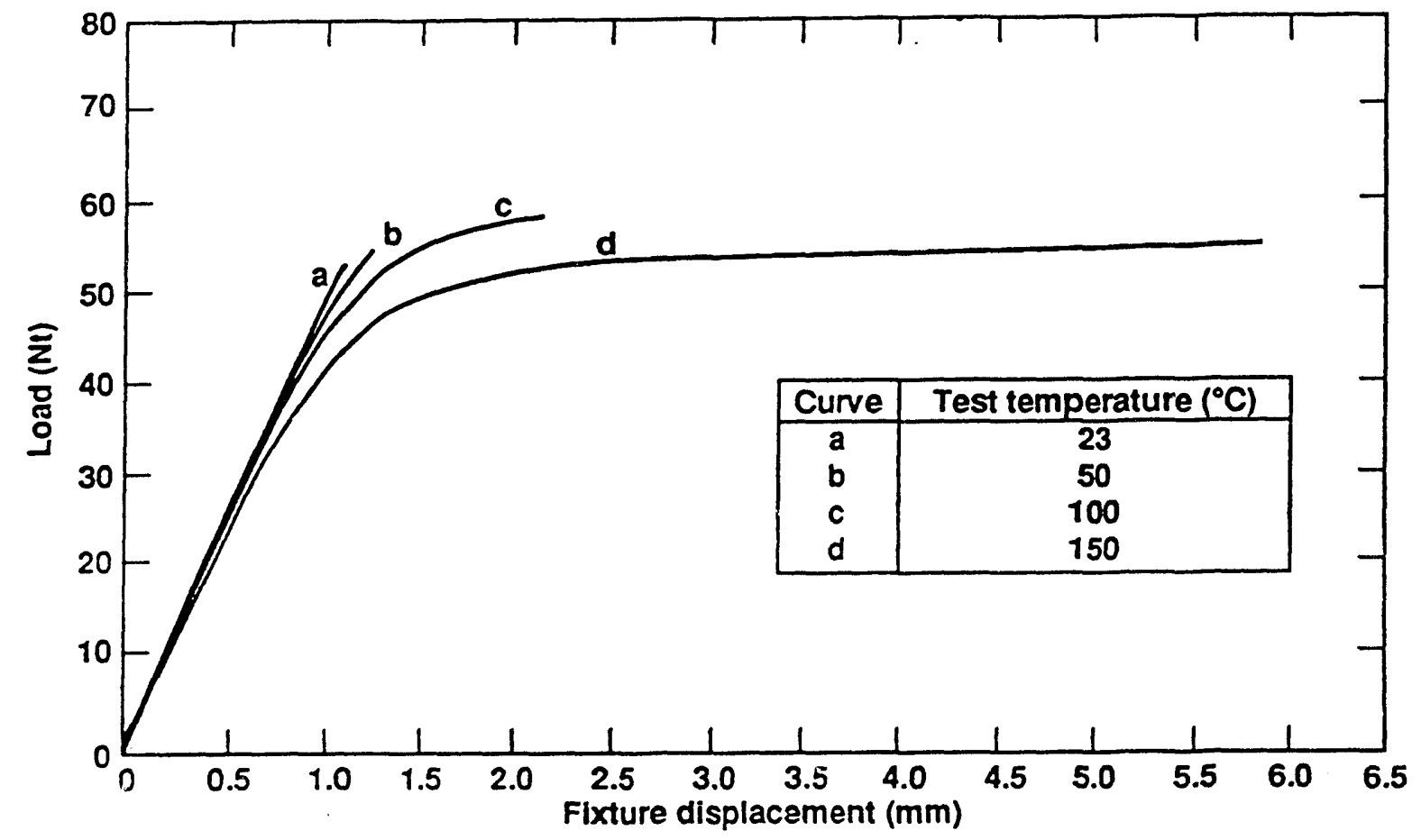

Figure 1. Plot of load versus fixture displacement for material WF-1. Considerable plastic deformation of the sample occurred at test temperatures of $100^{\circ} \mathrm{C}$ and $150^{\circ} \mathrm{C}$. 


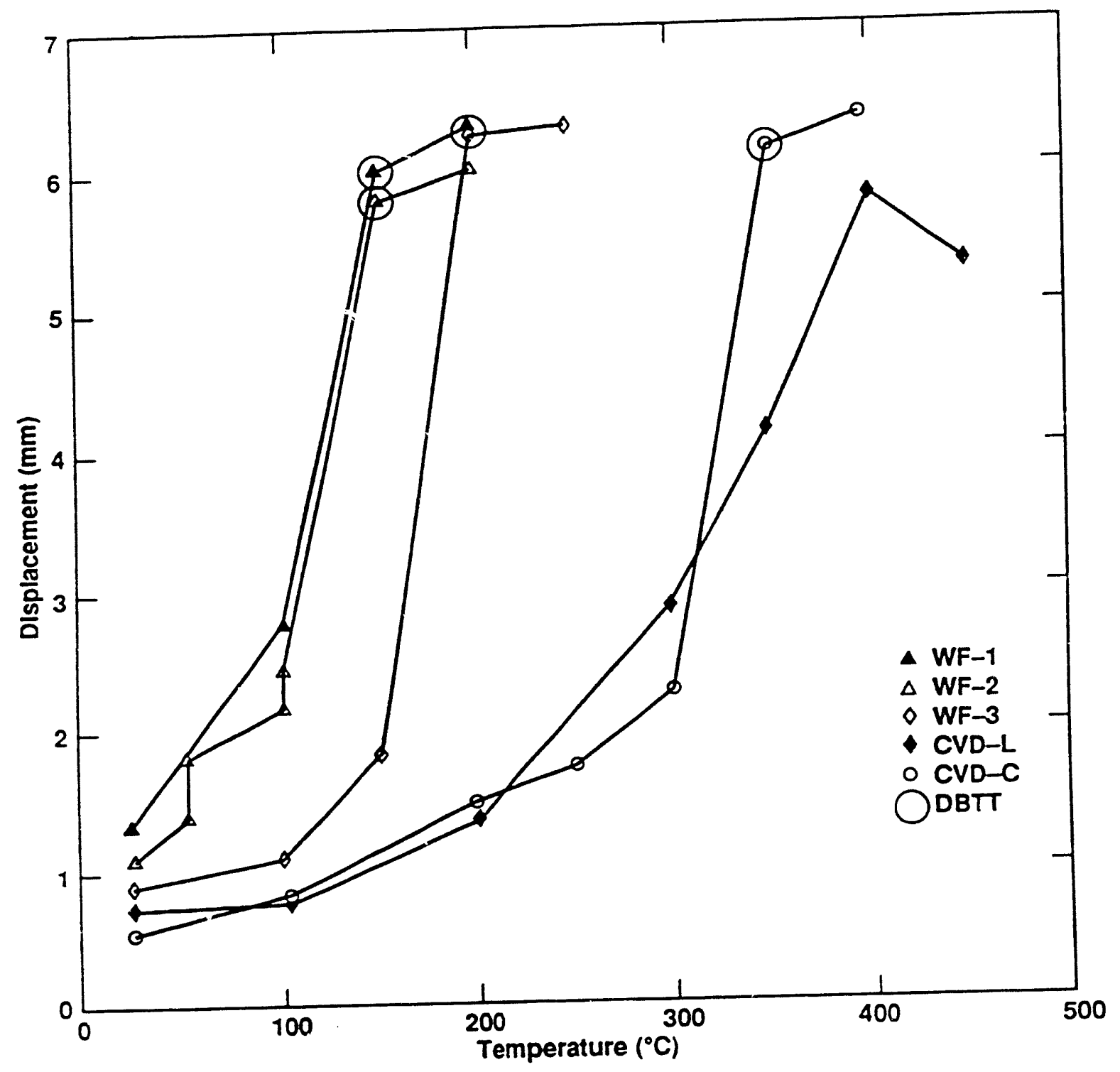

Figure 2. Maximum displacement of the test fixture versus test temperature. Circled data points indicate minimum temperatures at which the samples did not fracture and also indicate the DBTT (as defined in this work). 
bnd01: 3 pt. bend: ip 4 s. 1 .

$d s f=1.00000 e+00$

t $\mathrm{ime}=0$.

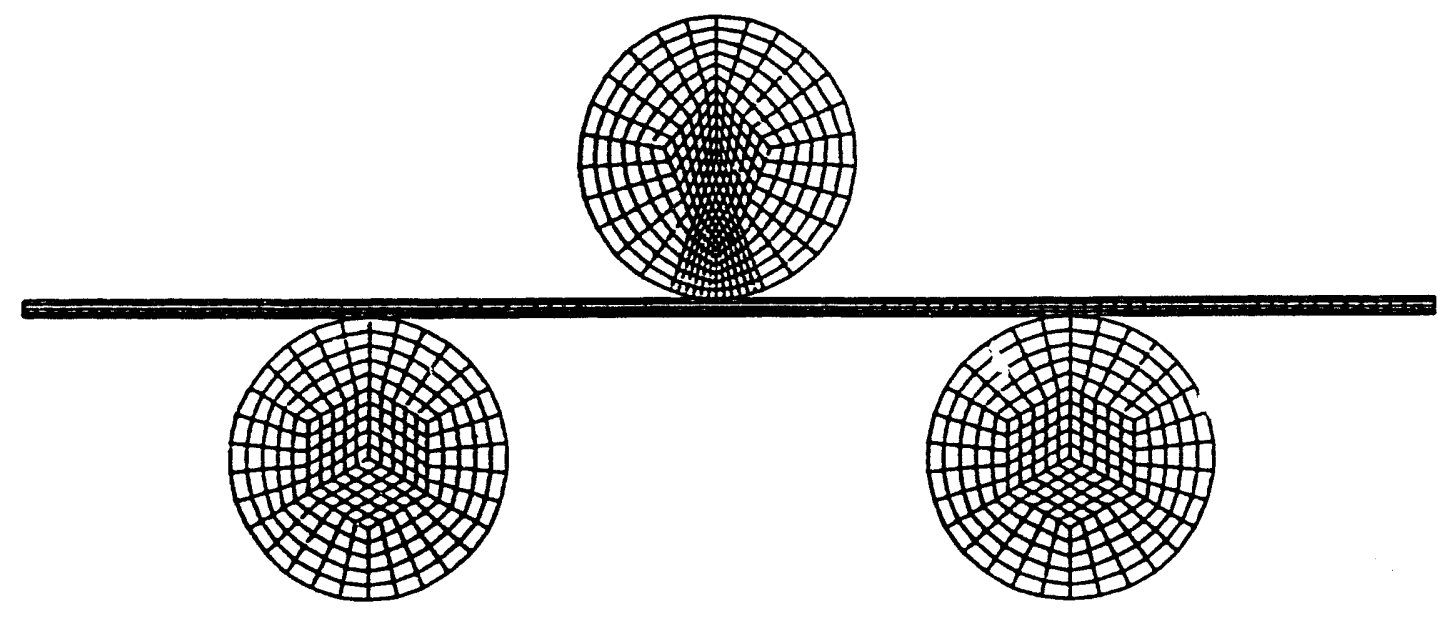

Figure 3. Mesh used for 2-D computer modeling of the three-point bend test. 


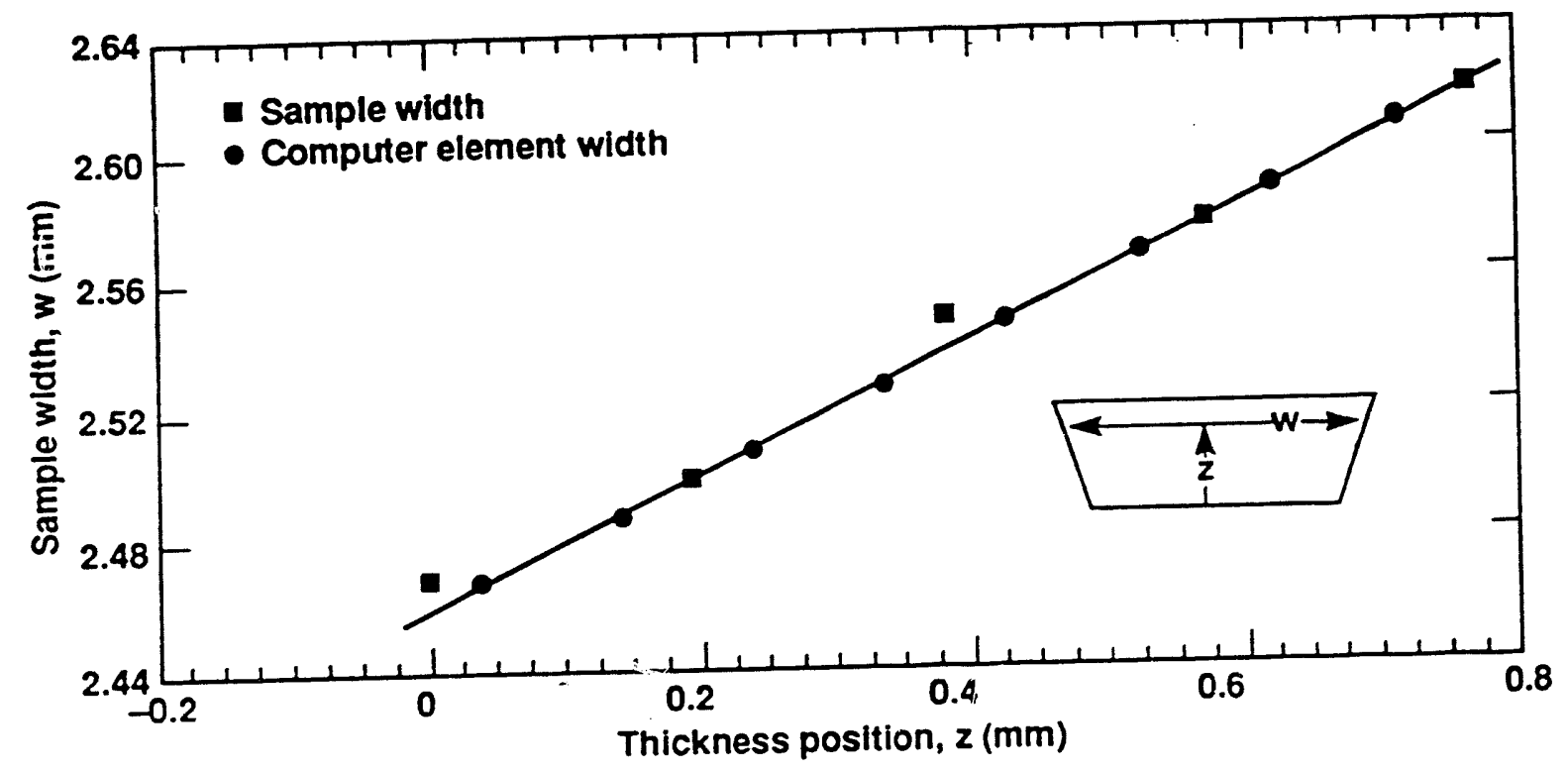

Figure 4. Plot of the sample width (sample measurement and computer model prediction) versus position through the sample thickness. This result validates the plane-stress assumption under which the calculations were performed. 


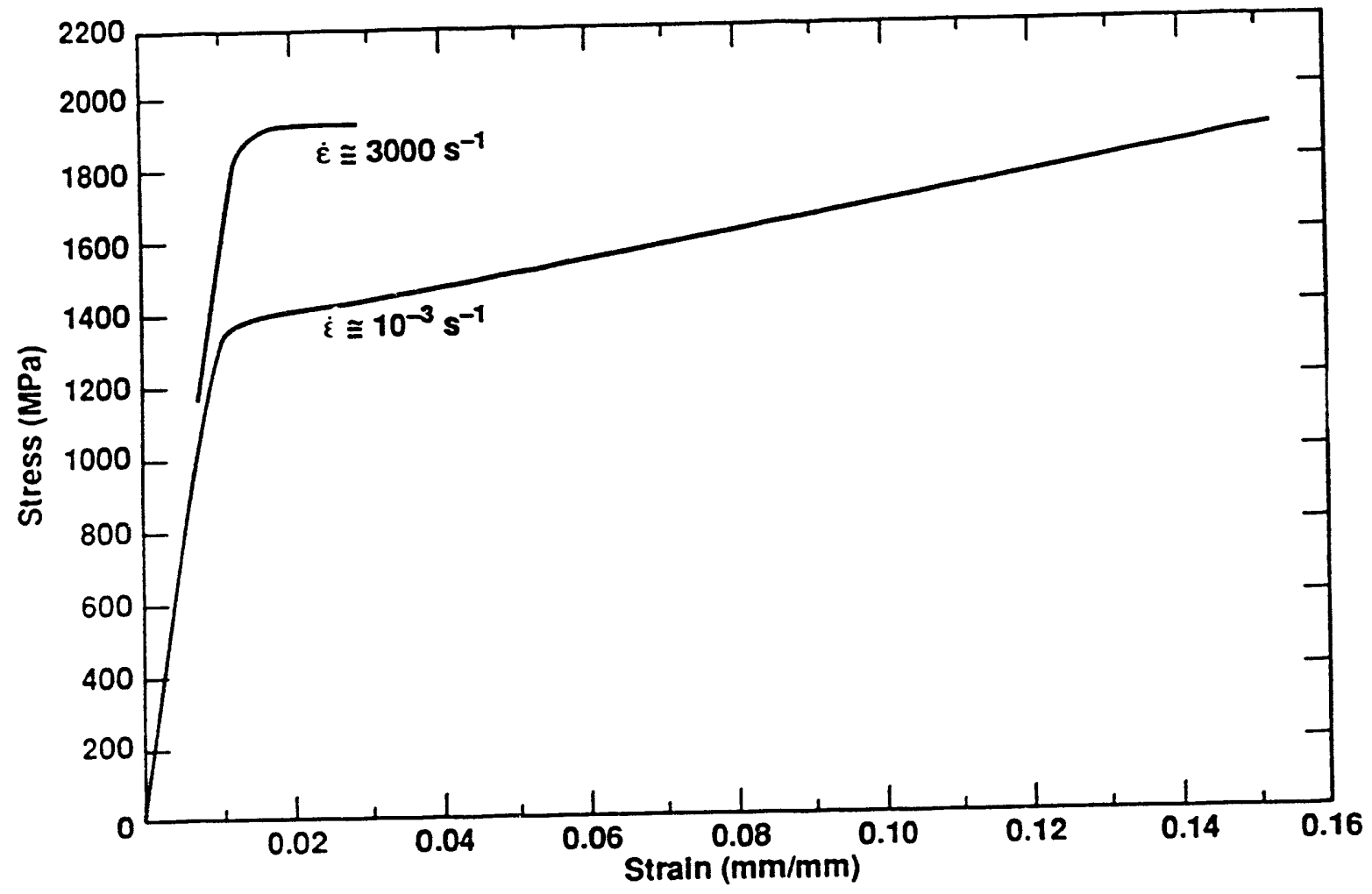

Figure 5. True stress-strain behavior of material WF-2 at strain rates of $10^{-3} \mathrm{~s}^{-1}$ and $3000 \mathrm{~s}^{-1}$. 


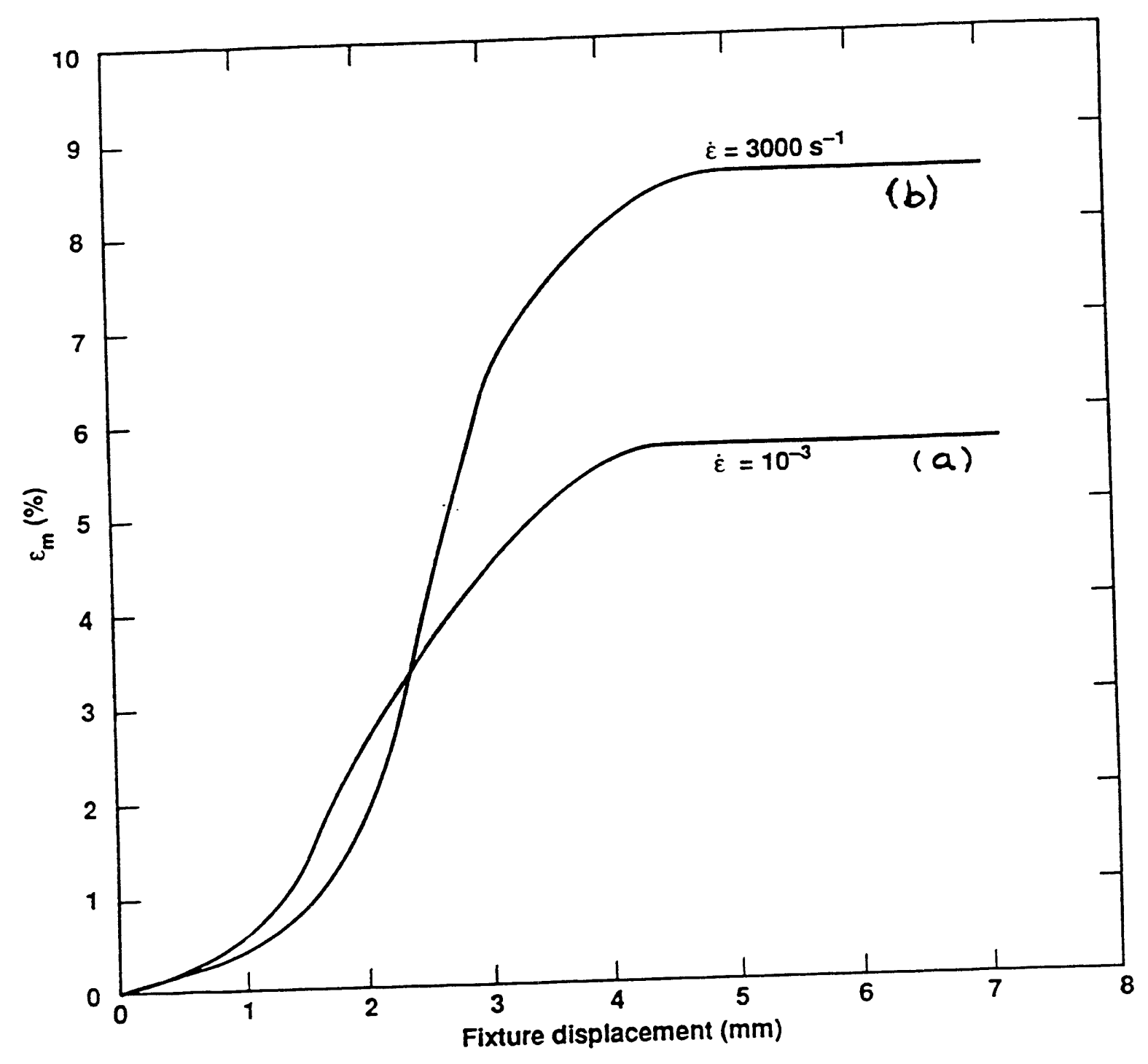

Figure 6. Computer model prediction of maximum strain as a function of fixture displacement for material WF-2 deformed at strain rates of $10^{-3} \mathrm{~s}^{-1}$ (curve "a") and $3000 \mathrm{~s}^{-1}$ (curve "b"). 


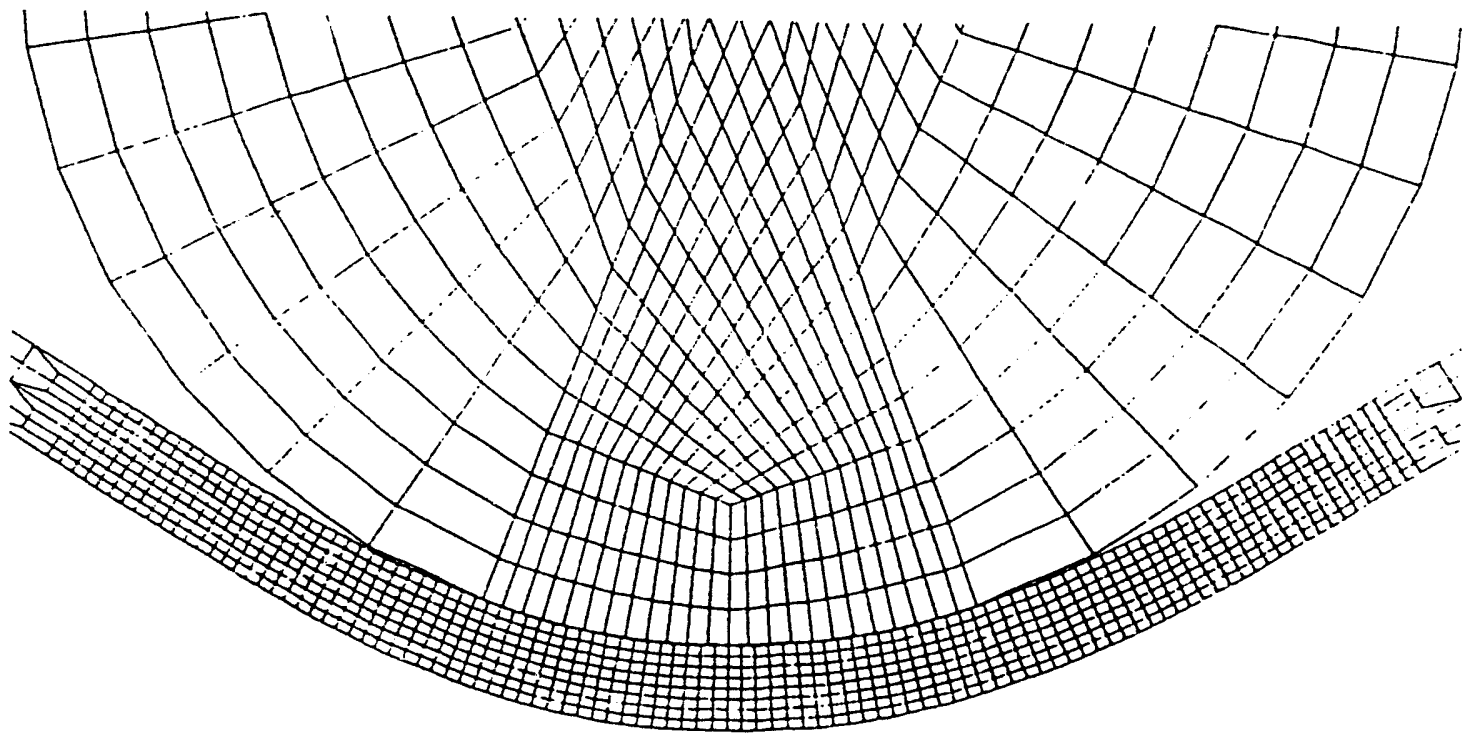

$7 b$

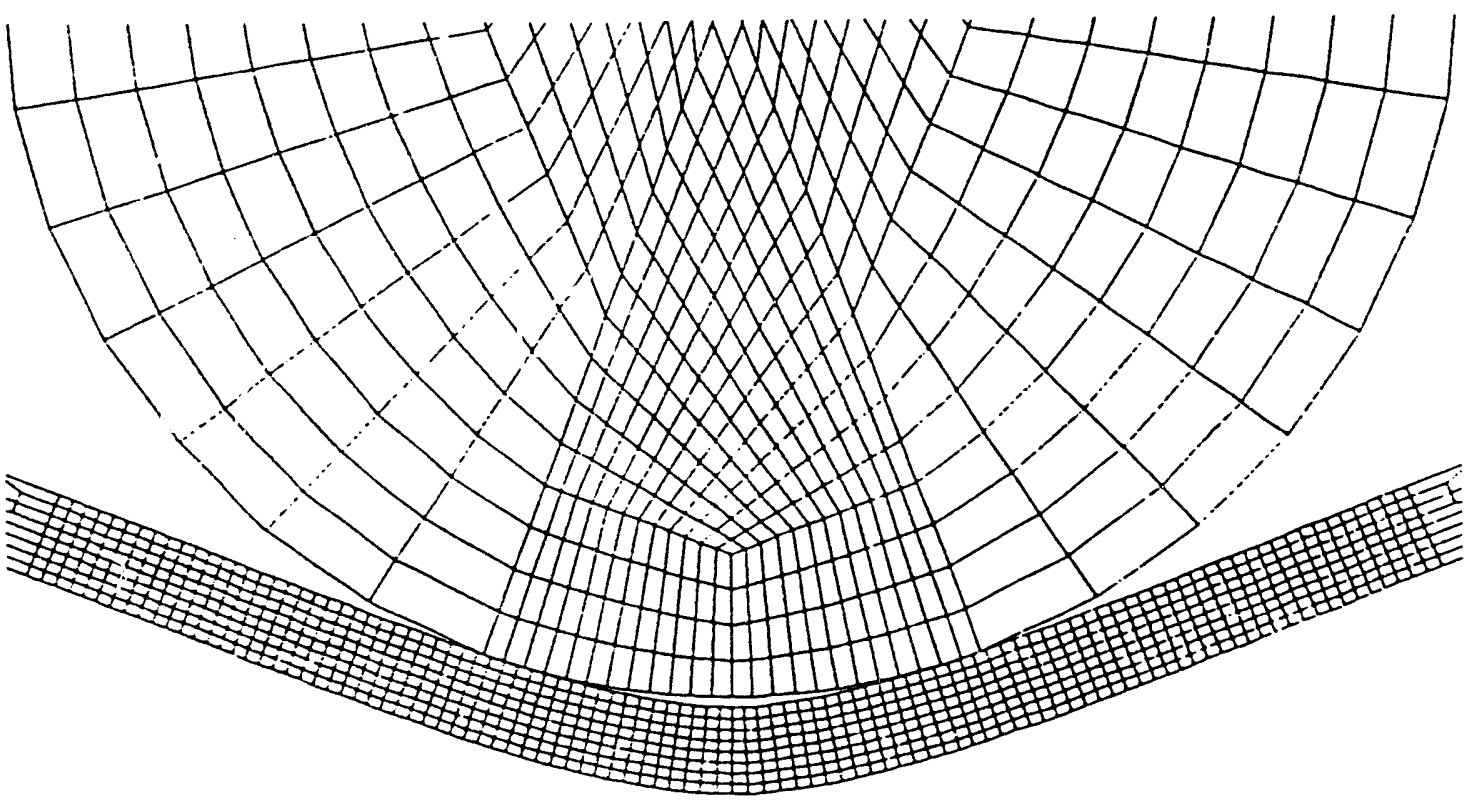

$13: 30: 15$

$03-26-91$

y machin

Figure 7. a) Computer mesh showing the deformed test sample (WF-2) conforming to the loading cylinder when deformed at a strain rate of $10^{-3} \mathrm{~s}^{-1}$. This output corresponds to curve "a" in Fig. 6 . b) Computer mesh showing the predicted WF-2 sample deformation at a strain rate of $3000 \mathrm{~s}^{-1}$. The sample losing contact from the loading cylinder is due to the development of a plastic hinge and results in large values of plastic strain. This output corresponds to curve "b" in Fig. 6. 


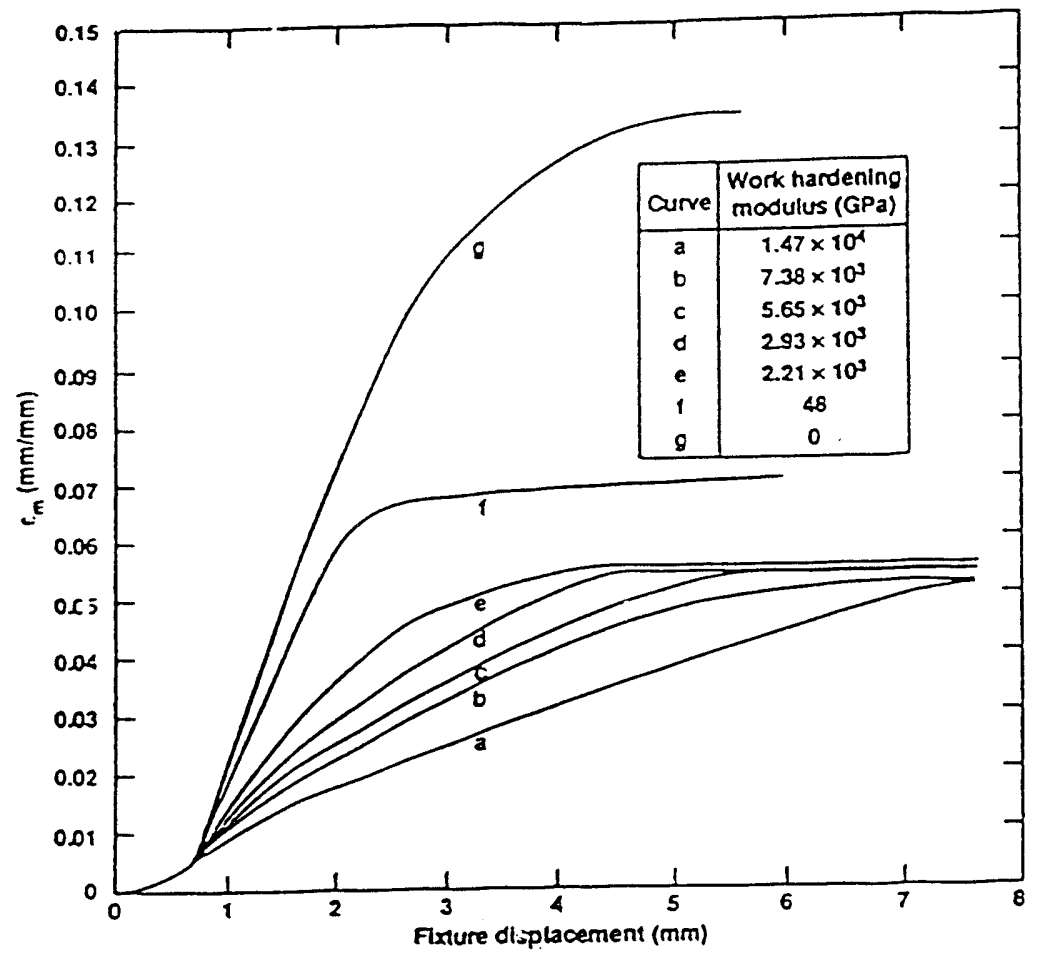

$8 \mathrm{~b}$

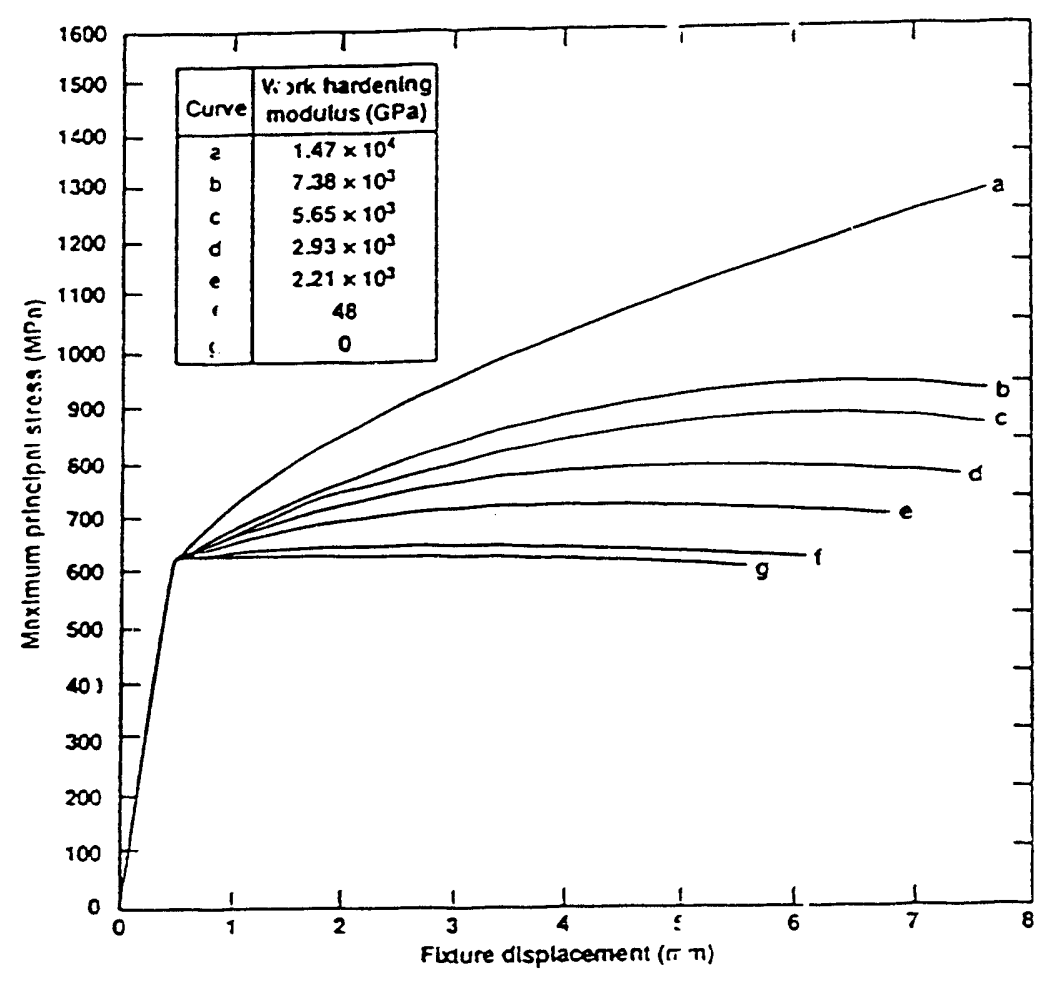

Figure 8. a) Computer prediction of maximum strain as a function of fixture displacement for different work hardening moduli. b) Maximum principal stress in the test sample corresponding to the curves shown in Fig. 8-a. 
$9 a$

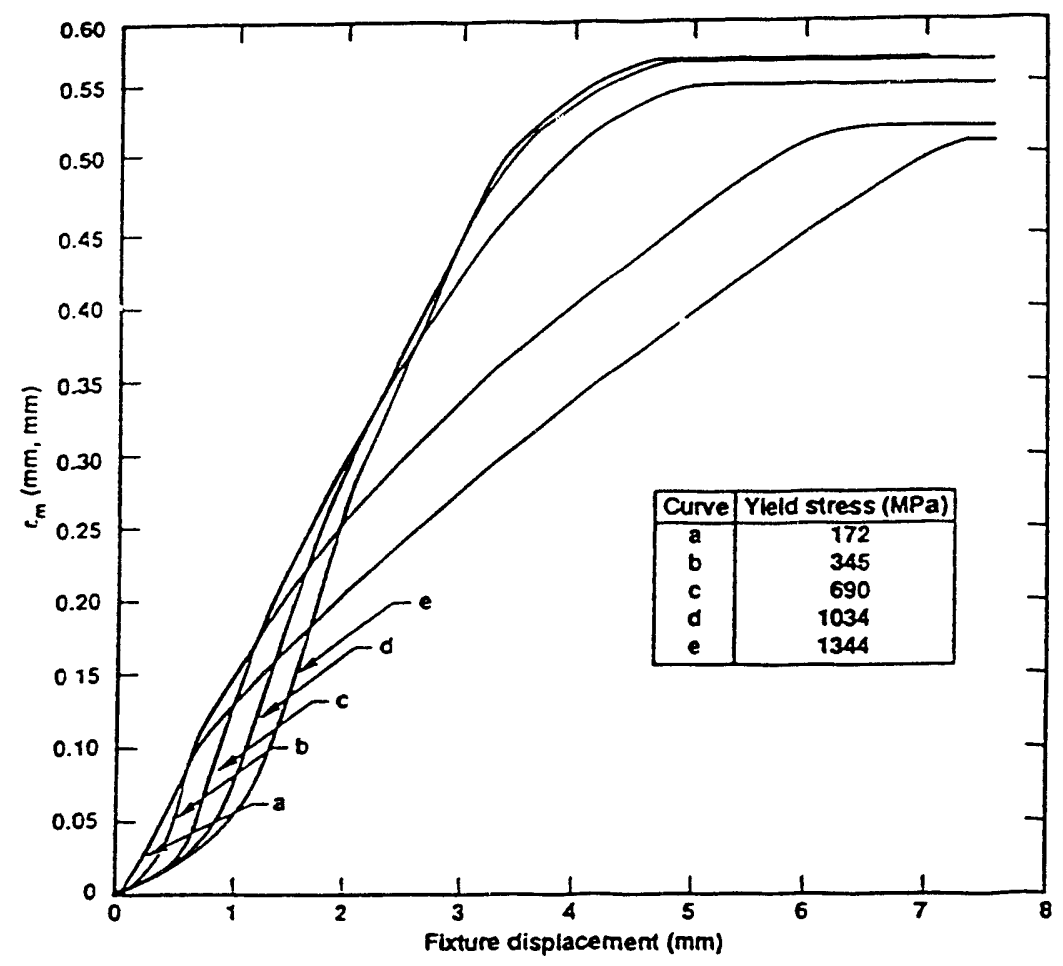

$9 b$

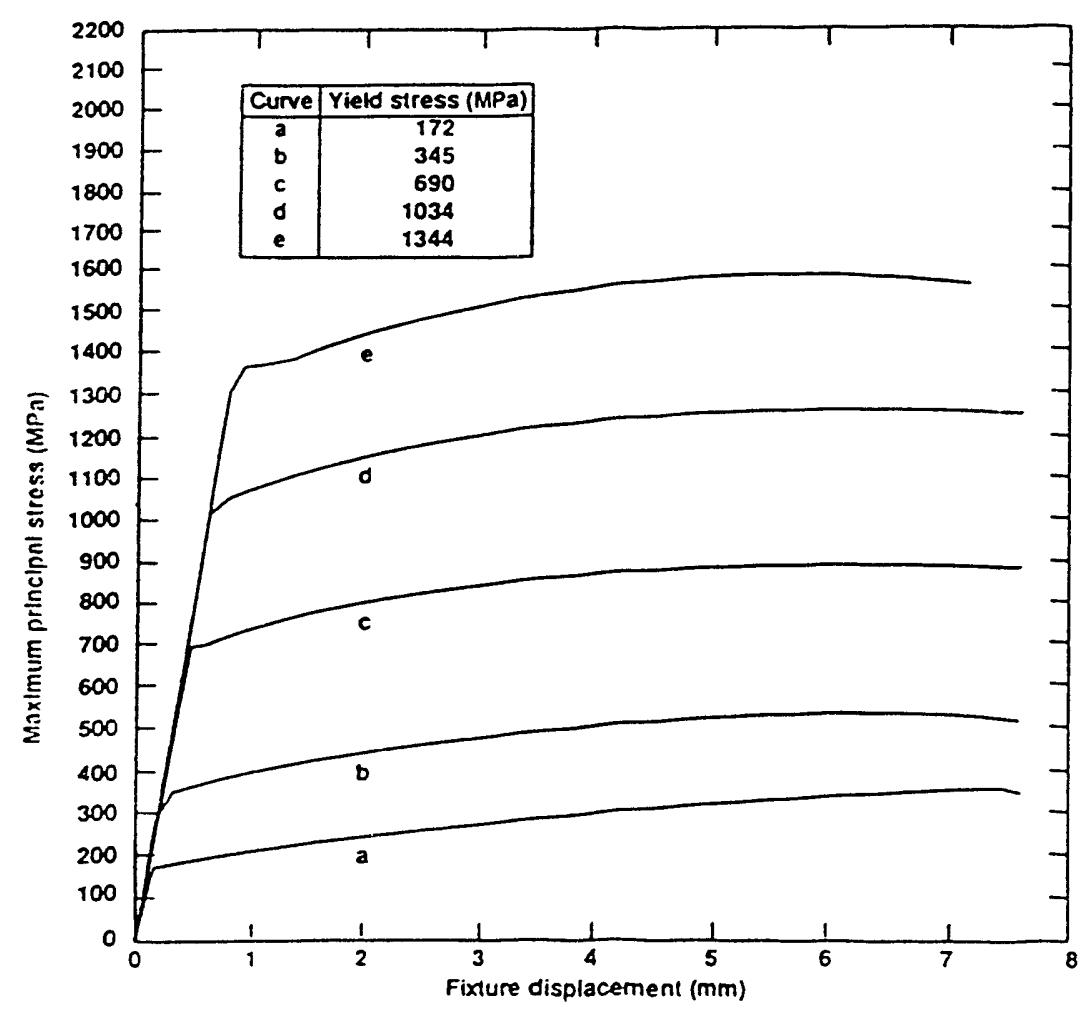

Figure 9. a) Effect of yield strength on maximum strain as a function of fixture displacement. b) Maximum principal stress in the test sample corresponding to the curves shown in Fig. 9-a. 

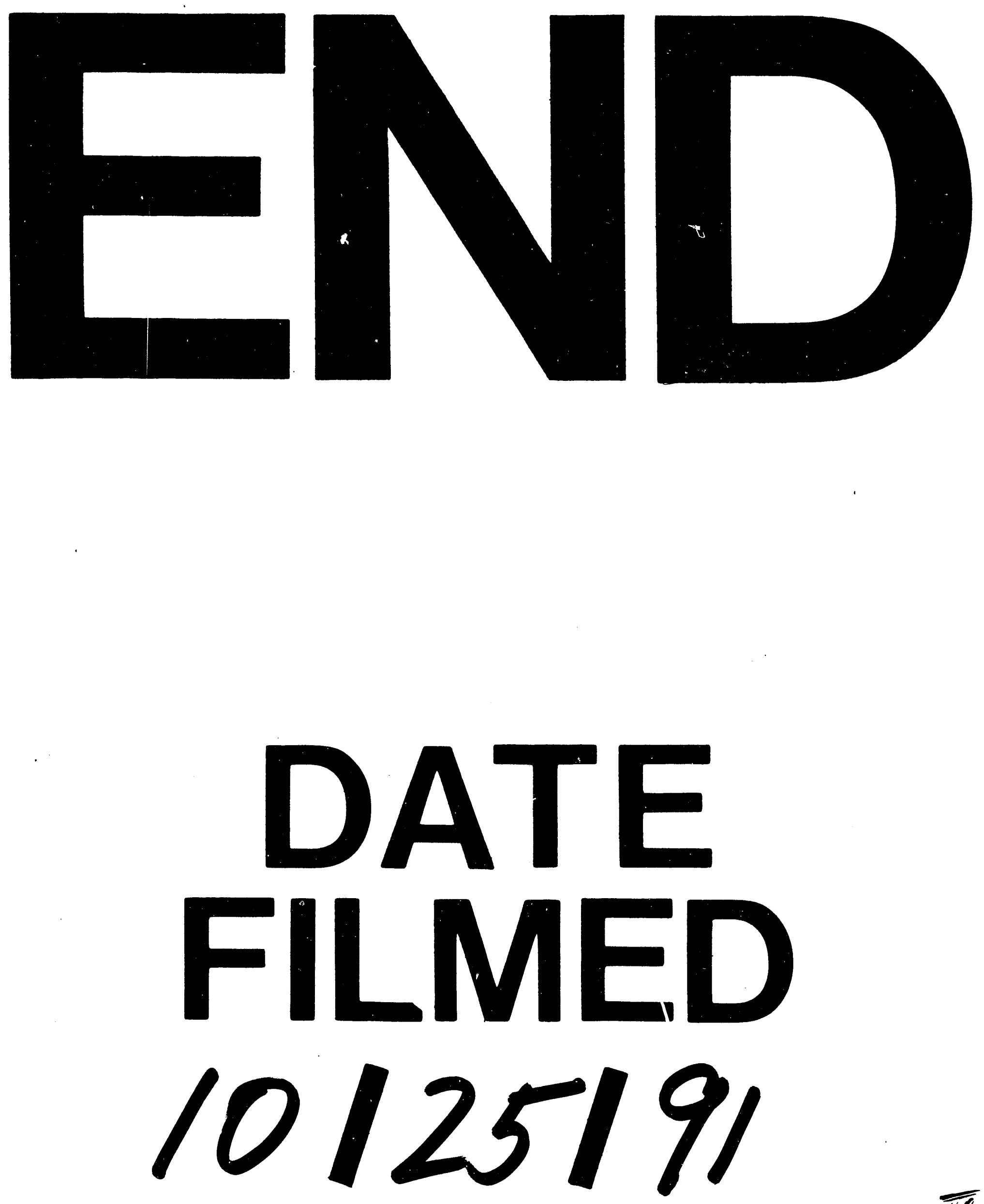

II 
, 